\title{
ARBITRAJE Y CONFLICTOS LABORALES EN EL PERÚ
}

\author{
PERU SUYUPI LLANKAQKUNAQ SASACHAKUYMANTA \\ HINALLATAQ ARBITRAJE NISQA KUCHKANCHAYWAN IMA \\ RUWAY \\ ARBITRATION AND LABOR CONFLICTS IN PERU
}

\begin{abstract}
Alí Félix León Charca ${ }^{(1)}$
Ch'uyanchakuy: Kay ensayupi, qelqaqmi churan kuskiqamanta chay conflictos sociales nisqamanta (sapallaychismanta, aska runaqmanta, juridico nisqamanta y economicos nisqata) Ilanqaqpi ruwakuykunata, akllarispa mastarispa hujhina nuqanchismanata, Chaymantaqa sayarimunampaq economico awqaypi, legislacion del derecho colectivo llankaymanta y arbitraje churasqapi, chaykunata tanichinampaq, cahy derechunchiskuna ruwasqa qolluriktin.
\end{abstract}

Yuyaysapa simichakuna: Qhapaq kayninmi, Kamachiy, Llak'aqkunaq Ilank'ayninpi sumaq kausayninta

Resumen: Este ensayo presenta una breve investigación sobre los conflictos (individuales y colectivos, jurídicos y económicos) que se producen en el trabajo, clasificándolos y explicando las diferencias entre ellos, para luego detenerse en los conflictos económicos, encuadrados en la legislación del derecho colectivo del trabajo y el arbitraje, como la forma de solución pacífica de aquellos, cuando los mecanismos auto compositivos diseñados por la ley, han fracasado.

Palabras clave: Conflictos laborales, Economía, Legislación, Solución pacífica.

Abstract: This essay presents a brief investigation about the conflicts (individual and collective, legal and economic) that occur in the work life, classifying them and explaining the differences between them, then stopping in the economic conflicts,

(1) Doctor en Derecho (UNSAAC), Maestro en Derecho del Trabajo y de la Seguridad Social (UNMSM - UAC), Abogado laboralista (UAC), Maestrista en Ciencia Política y gobierno (PUCP), docente de la Facultad de Derecho de la UNSAAC. 
framed in the legislation collective labor law and arbitration, as the form of peaceful solution of those, when self-designed mechanisms designed by law, have failed.

Key words: Labor conflicts, Economy, Legislation, Peaceful solution. 
Todo conflicto presupone siempre el antagonismo de dos o más intereses contrapuestos, estos últimos hallados casi siempre disfrazados en posiciones; o sea que, en toda pugna juegan indefectiblemente factores subjetivos tales como: sentimientos, pareceres, ideologías, cosmovisiones, criterios personalísimos y otros.

Algunos autores, consideran que dichos elementos, son los que precisamente dan forma a la magnitud de distancia que caracteriza a cualquier diferencia, olvidando el contenido mismo de los intereses humanos y sus conflictos, adecuadamente abordados por Roberto PADILLA (1996, p. 73), para quien:

El conflicto es parte de la vida en comunidad, no es un concepto objetivo, sino, más bien, subjetivo: en general, el conflicto es aquello que los individuos perciben como tal (...).

Las ideas que presentamos, derivan de una tesis radical para la cual, el conflicto no siempre tiene una connotación negativa, podría ser positiva y servir para fortalecer las relaciones huamanas. Pero esta afirmación (cuasi filosófica), es tan solo el punto de partida de la aproximación juridica que propone este ensayo.

A primera vista, pareciera hallarnos ante una afirmación de certeza dudosa, pero en un mundo en donde el conflicto es inevitable (y frecuentmente equiparado a cuestiones destructivas), resulta importante distinguirlo de las oportunidades que la situación concreta pueda presentar, tanto para sus protagonistas (de modo indirecto), como para toda la comunidad (de modo indirecto).

Cuando la violencia emerge, las oportunidades compenedoras de los intereses contrapuestos, menguan. Una premisa sociológica explica que la televisión, el cine y algunos otros presupuestos culturales, exaltan las virtudes de ser duro e intransigente; en este punto, es crucial destacar que el manejo no violento de los conflictos, constituye una forma de desarrollar habilidades esenciales para la vida en sociedad.

El trabajo -y su regulación- no es ajeno a los elementos propios de cualquier conflicto. Trabajadores y empleadores o trabajadores entre sí (sea que estén organizados o no), pueden protagonizar conflictos de trabajo de naturaleza diversa, cuya definición intentamos explicar en estas líneas.

Ivonne NEYRA SALAZAR (2014, p. 6), sobre las incompatibilidades inherentes al empleo refiere:

Los intereses antagónicos que se suscitan dentro de un contexto laboral, cuyos actores principales son los 
trabajadores y empleadores, conllevan a afrontar diversos conflictos laborales dentro de cada organización, que considerando que cada quién tiene sus propios y legítimos intereses, es necesario advertir a qué tipo de conflicto nos referimos a fin de manejarlo de la forma más adecuada dentro de un marco laboral para evitar controversias dilatadas y graves.

En relación a ello, y a fin de determinar cuál es la posición que el Estado debería adoptar en este tipo de conflictos es necesario contextualizar el régimen en el cual se encuentra el Perú. De esa forma, el modelo adoptado por nuestra actual Constitución Política de 1993 (en adelante la "Constitución") se encuentra respaldada en un régimen de Estado Social y Democrático de Derecho, considerando que el Estado parte del reconocimiento de los conflictos laborales como un problema natural y circunstancial de las relaciones laborales entre los sindicatos y las empresas, y no como un mal dañino a la sociedad. Al respecto, el Estado no es un tercero ajeno a dicha relación, más aún si consideramos que el rol que desempeña en dicho contexto laboral tiene entre una de sus principales labores el brindar a las partes los mecanismos de solución pacífica a sus conflictos.

El malogrado profesor y tratadista peruano Mario PASCO COSMÓPOLIS, recogiendo la clasificación propuesta por la OIT, sostiene que los conflictos laborales pueden ser individuales y colectivos; a su vez, de derecho y económicos.

Sobre los conflictos individuales de trabajo, manifiesta que son aquellos promovidos en el ámbito del contrato de trabajo; por tanto, su alcance se circunscribe a la satisfacción de los intereses de un trabajador (respecto de su empleador o empleadores), a quien el Estado le garantiza la reivindicación de los derechos a él reconocidos por la legislación o las demás fuentes del ordenamiento jurídico laboral; siendo esto así los conflictos individuales de trabajo, deben entenderse siempre como conflictos jurídicos, pues su propósito perseguirá siempre la aplicación y/o la interpretación de una norma legal (u otra fuente de derecho), según corresponda.

Por su parte, los conflictos colectivos de trabajo, son aquellos donde el interés en cuestión es común a un grupo o unión de trabajadores, sean que conformen un sindicato o una representación laboral cuyo propósito es mancomunado, homogéneo o igualitario.

Los conflictos colectivos de trabajo pueden ser de derecho o económicos. Serán conflictos de derecho (llamados también jurídicos): “(...) aquellos que [surgen] en la discrepancia existente entre los sindicatos y las empresas con respecto a la interpretación de una norma vigente, los mismos que usualmente aparecen cuando se produce el incumplimiento de obligaciones laborales de las 
empresas o simplemente cuando se trata de dos posiciones encontradas sobre la aplicación o interpretación de una norma" (NEYRA, 2014, p. 8).

Los conflictos de derecho individuales, como consecuencia de la vigencia de la Nueva Ley Procesal del Trabajo Nro. 29497, han sido súbitamente alejados de la posibilidad práctica de los arbitrajes en el Perú. A diferencia de su predecesora (Ley Nro. 26636) que, permitía la posibilidad de suscribir convenios arbitrales como parte del contrato de trabajo y en cualquier otro momento de la relación laboral, la nueva disposición adjetiva de trabajo, condiciona la validez del convenio arbitral a su suscripción posterior a la extinción del vínculo de trabajo, lo cual no solo resulta poco probable, sino prácticamente imposible, con lo cual, pensar en arbitrajes y laudos para los conflictos laborales de derecho, resulta quimérico.

Se entenderán por conflictos económicos:

"(...) aquellos que se derivan de intereses comunes de los afiliados a los sindicatos en contra de los que tienen las empresas, en cuyo caso, los primeros buscarán mejorar sus ingresos económicos y/o condiciones laborales y los segundos maximizar su capital dentro del marco de una negociación colectiva. A través de estos conflictos se intenta realizar modificaciones y/o cambios significativos en la normativa interna sobre expectativas económicas, las mismas que serán plasmadas en los convenios colectivos, las cuales se encuentran sustentadas en su naturaleza normativa" (NEYRA, 2014, p. 8).

Los conflictos económicos del trabajo; es decir, las negociaciones colectivas, se han constituido en el escenario natural para los arbitrajes en materia laboral, habiendo sido incluidos como etapa negocial y potestativa a la huelga, tal como lo ha definido la Ley de relaciones Colectivas de Trabajo (Decreto Ley Nro. 25593) en su texto original y posteriormente en su Texto Único y Ordenado (Decreto Supremo 010-2003-TR).

Antes de adentrarnos en el tema de la justicia privada en materia colectiva de trabajo (o sea arbitrajes), resulta indispensable revisar conceptos sobre la inescindible relación entre el conflicto y los diversos procesos diseñados por el Derecho, para su eventual solución. Al respecto dice Roberto PADILLA (1986, p. 75):

"Es tradicionalmente aceptado y aconsejado buscar en la ley el equilibrio de justicia que las disputas reclaman. El proceso legal irradia la promesa de justicia. La gente está persuadida de que la ley garantizará sus derechos, reservará su libertad y protegerá su propiedad. 
Cuando las partes en disputa no pueden reconciliar sus posiciones, el litigio aparece estructurando el melodrama del conflicto humano a través de un conjunto de procedimientos diseñados para resolverlo. El ritual legal, con sus compulsivos niveles de debido proceso, puede contener las emociones exageradas de los disputantes, que de otra manera podrían provocar la venganza privada o la violencia pública. Indudablemente, la sociedad se beneficia entonces con este procedimiento forma legal, y la sola idea de audiencia de Tribunales estatales y de abogados, inspira temor al caos".

Pero la ley y el litigio tienen un lado oscuro. El camino judicial en ocasiones es inaccesible y exorbitante, sobre todo para la gente de escasos o menores recursos. El litigio, por su naturaleza eminentemente adversarial y adjudicativa, acentúa sentimientos de hostilidad, desconfianza, competencia y egoísmo. Una vez del conflicto se enmarca adversarialmente, se produce inevitablemente una competencia agresiva que destruyen a la empatía recíproca que podía haber existido entre las partes. La autonomía de las partes, su protagonismo, su capacidad, habilidad o responsabilidad para manejar sus diferencias, se va desvaneciendo hasta ser casi totalmente oculta bajo la idea que una vez depositado el conflicto en los tribunales, la decisión -y por lo tanto el problema- es del juez. Las partes se den así un espacio vital para mantener el control del caso. A medida que el proceso legal va avanzando, cada vez se aleja más la posibilidad de recuperar el protagonismo y operar en procura de una solución consensuada.

Los medios alternativos de resolución de conflictos denominados "MARCs", y los principios recientemente reintroducidos en las legislaciones procesales de América Latina (particularmente el mal llamado principio de oralidad), buscan atacar el flagelo que desde hace años azota la jurisdicción en esta parte del mundo, nos referimos a la denominada sobrecarga procesal o propiamente congestión judicial.

Este vicio o desviación en las políticas jurisdiccionales, debe entenderse como el déficit que se crea entre el número órganos de administración de justicia respecto del volumen de procesos judiciales asignados por despacho y no solamente el número de ingresos de nuevos expedientes por juzgado, de modo tal que el desempeño del operador de justicia, agota todos los esfuerzos que le permiten alcanzar la tan ansiada "carga cero", como referente de gestión judicial eficiente o lo que equivale a presentar en breves tiempos, que los expediente ingresados se han sentenciado.

La justicia privada o arbitraje, es un medio heterocompositivo para la solución de conflictos legales en diversas materias, en relación al tema y siguiendo las ideas del profesor Roque CAIVANO (1998, p. 223), citamos que: 
En los últimos tiempos se está verificando un paulatino renacer del arbitraje en Latinoamérica. La mayoría de los países está modernizando y actualizando sus leyes de arbitraje, se ha incrementado el interés en ratificar convenciones internacionales vinculadas al tema y es creciente la realización y la participación en jornadas, congresos o seminarios donde se estudie el arbitraje. Si bien esto no parece ser novedoso, la diferencia respecto de lo que sucedía años atrás, es que el tema está evolucionando, desde la expresión de deseos de quienes venimos predicando desde hace tiempo sus bondades, hacia el campo de la práctica cotidiana. Es posible aseverar que ya no son pocos los contratos en los que se pacta la jurisdicción arbitral y dejaron de ser minoría los abogados que sugieren a sus clientes acudir a este mecanismo alternativo. Obviamente no existe todavía en la mayoría de los países de América Latina, una considerable cantidad de casos sometidos a resolución de árbitros, pero sin duda no tardará mucho en haberlos, porque -como demuestra la experiencia-, suele transcurrir algún tiempo desde que el arbitraje se pacta hasta que los casos comienzan a llegar a los tribunales arbitrales.

La Declaración Universal de los Derechos del Hombre y del Ciudadano (del 26 de agosto de 1789), proclamada al cabo de la Revolución Francesa, dio lugar a la progresiva implementación de legislaciones nacionales que llevaron al escenario práctico y con carácter primordial el principio de libertad.

El Código Civil francés de 1804, denominado oficialmente desde 1807 como Código Napoleónico, desarrolló en Europa a nivel legislativo común, la noción de la libertad implementada en la propiedad privada, siendo que sustantivamente ha servido de inspiración a las diversas legislaciones civiles con raíces romanogermánicas.

En el ámbito procesal, la encarnación institucional del principio de libertad es el arbitraje. Sostiene Roque CAIVANO (1998, p. 228) que:

"Si una persona -en su esfera de libertad y autonomía de voluntad- puede renunciar a un derecho propio, parece un principio natural que pueda también entregar la suerte de su derecho a la decisión de un particular que inspire confianza. La jurisdicción, en definitiva, no importa un ejercicio monopólico a través de los órganos del Estado; al ser una función establecida en el interés y protección de los particulares, estos podrán, en el campo de los derechos que pueden disponer libremente, escoger un sistema privado, al que -por añadidura- la propia ley le otorga naturaleza jurisdiccional".

El arbitraje puede ser así una de las fórmulas a través de las cuales se asegure los ciudadanos el acceso a una justicia eficiente, administrada por las 
mismas partes dentro de su esfera de libertad llegue el marco de sus derechos disponibles. Analizando su función en la sociedad, se ha dicho que

"acaso ninguna institución de las que encierra el ordenamiento jurídico de un país, rebelde con más hondo significado el sentido que el Derecho ocupa en su vida social, como la institución del arbitraje. El conjunto de normas que tienen por misión científica repartir con criterio de justicia, los distintos bienes humanos entre los miembros de una colectividad, está destinado, por la propia naturaleza de las cosas, a sufrir la ruda prueba que los conflictos de los intereses afectados le plantean diariamente. $Y$ puestos frente a la necesidad de ordenar igualmente esos conflictos e intereses, el derecho, antes de llegar al puro mecanismo coactivo de la intervención inapelable del Poder Público, idea una serie de mecanismos de conciliación que tratan de restablecer, en la medida de lo posible, el interrumpido orden de la convivencia social. Tal es precisamente el papel que asume el arbitraje dentro del problema general de las instituciones jurídicas"(2).

No solo a partir de la vigencia del Decreto Supremo Nro. 014-2011-TR (Regulación del Arbitraje Potestativo Laboral), consideramos que el carácter potestativo de los arbitrajes laborales, se encuentra definido incluso por el T.U.O. de la Ley de Relaciones Colectivas de Trabajo.

Coincidiendo con Ivonne NEYRA, el arbitraje diseñado y vigente en nuestro país es uno de naturaleza potestativa y excluyente respecto de la huelga (ambos institutos integran la etapa negocial al vencimiento de la conciliación/mediación), aunque no necesariamente el Tribunal Constitucional haya sido de este parecer, pues resulta que en sus casi siempre contradictorias resoluciones en el ámbito del trabajo, ha llegado a plantear la alternatividad entre la huelga y arbitraje ${ }^{(3)}$, incluso con carácter sucesivo y reiterado; empero, resulta indispensable citar a la refrida autora, para quien:

"El arbitraje potestativo, como forma de resolver un conflicto de intereses colectivos, según nuestro actual ordenamiento jurídico, establece dos fases muy marcadas durante el desarrollo del proceso arbitral. La primera es la etapa de admisibilidad, a través de la cual los árbitros

(2) Exposición de motivos de la Ley Española de Arbitraje del 22 de diciembre de 1953.

(3) STC. N $N^{\circ}$ 02566-2012-PA/TC, f.j.18. 
designados evalúan los supuestos alegados por la parte que solicita el arbitraje, y determinan si se trata de la primera negociación y/o si la otra parte incurrió o no en actos de mala fe o se trata de una primera negociación colectiva, se declara la procedencia del arbitraje potestativo, para luego pronunciarse sobre el tema de fondo, que es la segunda etapa de este proceso, en donde las partes presentan sus propuestas en forma del proyecto de convenio colectivo para que una de ellas sea acogida dentro del proceso arbitral. Por otro lado, si bien el tribunal arbitral solo puede acoger la propuesta de una de las partes, ello no implica que tenga que ser admitido en su forma integral, toda vez que los árbitros pueden atenuar aquellos beneficios planteados de forma excesiva o reducida (...)" (NEYRA, 2014, p. 55).

Finalmente, existen posiciones discrepantes en nuestra doctrina y jurisprudencia nacional e internacional, con respecto a la constitucionalidad y legalidad del arbitraje potestativo; sin embargo, actualmente esta herramienta al ser ya de aplicación en el marco de las relaciones laborales, ha tenido un fuerte impacto en la variación de las estrategias de las partes y un cambio en el comportamiento de las mismas. Definitivamente, la forma cómo enfrentaban los procesos de negociación colectiva han variado.

Por parte de los sindicatos, ahora es necesario que evalúen si les conviene declararse en una huelga o no, porque en caso lo hagan ya no podrían someterse a un arbitraje potestativo; $y$, por otro lado, deben evaluar los costos adicionales de una modalidad arbitral, los cuales son muy significativos comparado a otras alternativas de solución de conflicto. Los sindicatos tienen hoy en el arbitraje potestativo una institución para presionar a las empresas, para exigir cumplimientos de plazos, acceso a la información, observaciones a las obligaciones legales y en general actos que califiquen de buena fe negocial.

Por parte de las empresas ha implicado una adecuación en los procesos internos (por ejemplo, por un lado, en el suministro de información; y, por el otro, en el cumplimiento de plazos para la convocatoria del inicio de negociación), y probablemente realizar una mejor propuesta para no someterse al arbitraje potestativo. Una estrategia basada en dilatar la negociación y entorpecerla o no presentar alguna propuesta no es, a la fecha, una opción viable dado que este tipo de comportamientos son causales de arbitraje potestativo (2014, p. 139).

En relación a la atenuación arbitral laboral -principal característica de los laudos arbitrales en materia de trabajo- NEYRA (2014, p. 114), sostiene que: 
La Ley de Relaciones Colectivas de Trabajo y el Reglamento de la Ley de Relaciones Colectivas de Trabajo(4), establecen que el tribunal arbitral deberá recoger de forma integral la propuesta final de alguna de las partes sin que puede establecerse una solución distinta ni cambiar los planteamientos de una y otra. Esto significa que, por regla general, solo se podrá acoger la propuesta del sindicato de empresa, no pudiendo generar una tercera propuesta distinta a aquella planteada por las partes o una propuesta que contemple una mixtura de ambas.

Sin embargo, la virtud del principio de equidad cuando el tribunal arbitral determina que existen aspectos extremos en la propuesta suelen atenuarla, precisando la modificación y las razones que los han llevado a adoptar dicha situación. De esta forma, podríamos sostener que la atenuación es una forma excepcional de mitigar los excesivos o reducidos beneficios planteados por las partes. Así, si bien el auto no puede establecer una solución diferente a las propuestas planteadas por las partes ni realizar combinaciones entre ellas, si puede atenuarlas, por razones de equidad.

\section{Conclusiones}

10 "El mayor bien para un Estado, no es la guerra ni la sedición, sino la paz y la buena inteligencia entre los ciudadanos" (PLATÓN, 1979).

$2^{\circ} \quad$ En lo adjetivo, el arbitraje es para el principio de libertad, lo que la propiedad privada constituye para ese mismo principio, en lo sustantivo.

$3^{\circ} \quad$ Las mismas razones que han animado a establecer medios alternativos para la solución de conflictos civiles o puramente privados, las ha tenido el Derecho del Trabajo, para promover "MARCs" en sus procesos y procedimientos.

$4^{\circ} \quad$ Por la vigencia de la Nueva Ley Procesal del Trabajo Nro. 29497, la preocupación del Derecho del Trabajo se concentra casi de modo exclusivo, en la conflictividad económica que ha determinado al arbitraje potestativo, como etapa de la negociación colectiva, compartiendo esa categoría con el derecho de huelga. $5^{\circ} \quad$ Más allá de los desatinos del Tribunal Constitucional en materia de Trabajo, la vigencia del Decreto Supremo 014-2011-TR, ha ratificado el carácter potestativo del arbitraje laboral y en nuestro concepto, excluyente de la huelga; razón por la cual, no nos hallamos ante institutos alternativos y sucesivamente alternativos, como lo ha sostenido el supremo interprete y contralor de la constitucionalidad.

$6^{\circ} \quad$ La principal característica y elemento distintivo de los laudos arbitrales en materia de trabajo, responde al mandato expreso de los Artículos $65^{\circ}$ del T.U.O. de la Ley de Relaciones colectivas de Trabajo y $57^{\circ}$ del Reglamento de la Ley de Relaciones Colectivas de Trabajo, inspirados ambos en el principio de equidad, el cual "es un momento en la dialéctica de búsqueda de la justicia" (sic), siguiendo la idea de Fernando DE TRAZEGNIES (1998, p. 116). 


\section{Bibliografía}

CAIVANO, R. (1998). "Arbitraje". En R. CAIVANO (Ed.), Negociación, Conciliación y Arbitraje (pág. 228). Lima, Perú: Asociación Peruana de Negociación, Arbitraje y Conciliación - APENAC.

DE TRAZEGNIES, F. (1998). "Arbitraje de derecho y arbitraje de consciencia". En IUS ET VERITAS. No. 12. Lima, Perú: Asociación Civil IUS ET VERITAS.

NEYRA, C. I. (2014). El arbitraje potestativo como forma de solución de conflictos laborales. Lima, Perú: Pontificia Universidad Católica del Perú.

PADILLA, R. (1996). La negociación como mecanismo apropiado de gestión de conflictos. En R. CAIVANO (Ed.), Negociación, Conciliación y Arbitraje (pág. 73). Lima, Perú: Asociación Peruana de Negociación, Arbitraje y Conciliación - APENAC.

PLATÓN. (1979). Las Leyes. México, México: Porrúa. 